\title{
Immunofluorescence studies of the distribution of gastrin cells in different clinical states
}

\author{
A. G. E. PEARSE AND G. BUSSOLATI ${ }^{1}$ \\ Royal Postgraduate Medical School, Hammersmith Hospital, London
}

SUMMARY Examination of human gastric biopsies by an indirect immunofluorescence technique using antihuman gastrin confirms the variability in distribution and number of gastrin-secreting (G) cells (Solcia, Vassallo, and Capella, 1969) observed by morphological, cytochemical, and electron microscopical studies. In cases with presumed secondary hypersecretion a profound degree of G-cell hyperplasia is observed. Immunofluorescence with. antigastrin can provide valuable information on the state of the $G$ cells in different physiological states, particularly if used in conjunction with other cytochemical techniques.

An immunofluorescence technique was first used successfully by McGuigan (1968) to demonstrate gastrin in the porcine and human antrum. The fluorescent cells were identified as similar to those of certain classes of enterochromaffin cells but they could not be identified as argentaffin or argyrophil. In the case of the porcine antrum the cells fluorescing after the application of antigastrin sera were identified by Bussolati and Pearse (1970) as the argyrophil $G$ cells described by Solcia et al (1969). This paper describes the application of an indirect immunofluorescence technique to the study of the distribution of $G$ cells in the human pyloric antrum in different clinical states.

\section{Materials and Methods}

Biopsies of human antral mucosa were removed from the capsule and fixed immediately in cold $\left(4^{\circ} \mathrm{C}\right) 4 \%$ formaldehyde prepared from paraformaldehyde according to the procedure of Graham and Karnovsky (1966). Subsequently they were washed for two to 24 hours in $30 \%$ sucrose in

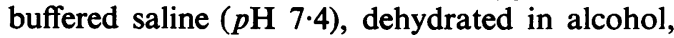

1Present address: Instituto di Anatomia Patologica, Universita di Torino, Italy.

Received for publication 13 March 1970. cleared in xylene, and embedded in paraffin wax Sections were cut at $5 \mu \mathrm{m}$ and brought down to buffered saline through xylene and graded alcohols. They were processed by an indirect immunofluorescence technique. The antigastrin serum (a gift from Professor K. W . Rees, University College Hospital, London) was prepared by immunizing rabbits with synthetic human gastrin bound to bovine serum albumin by the procedure used by McGuigan (1968). The presence of antigastrin antibodies was assessed by radioimmunoassay.

The indirect immunofluorescence procedure was carried out with sections first treated either with unlabelled antigastrin serum, or unlabelled antigastrin serum absorbed with bovine serum albumin to remove antibovine serum albumin antibodies, or normal rabbit serum.

Subsequently all sections were treated with goat antirabbit $\gamma$-globulin labelled with fluorescein isothiocyanate and passed through DEAEcellulose columns (Wood, Thompson, and Goldstein, 1965). The fractions obtained by eluting with 0.1 and $0.05 \mathrm{M}$ phosphate buffer were concentrated before use.

\section{Results}

Control sections, treated with normal rabbit 


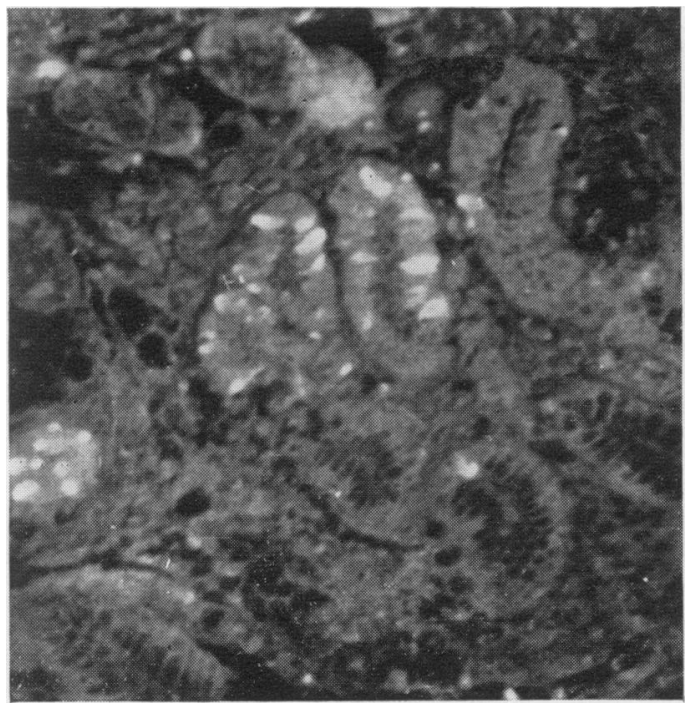

Fig. 1. Normal human stomach, female 26 years, pyloric region. Radiological and gastrin secretion tests normal. $G$ cells are present in moderate numbers in the pyloric glands, mainly in the mid portion $(\times 87)$.

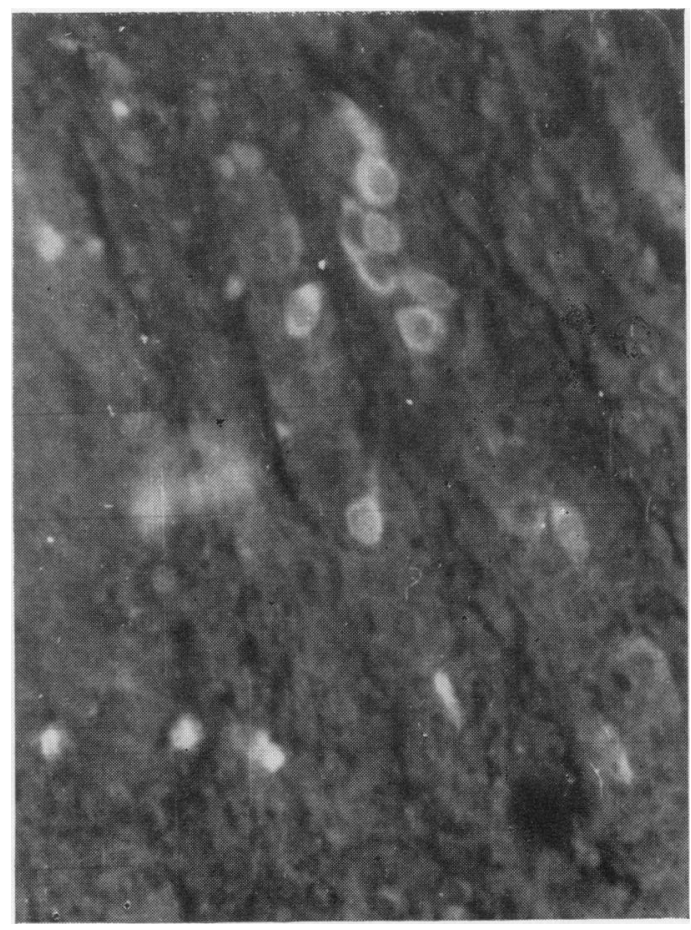

Fig. 3. Normal pyloric antrum. Higher magnification of cells from the same antrum as in Figure 1. Shows individual G cells in mid-zone glands $(\times 420)$.

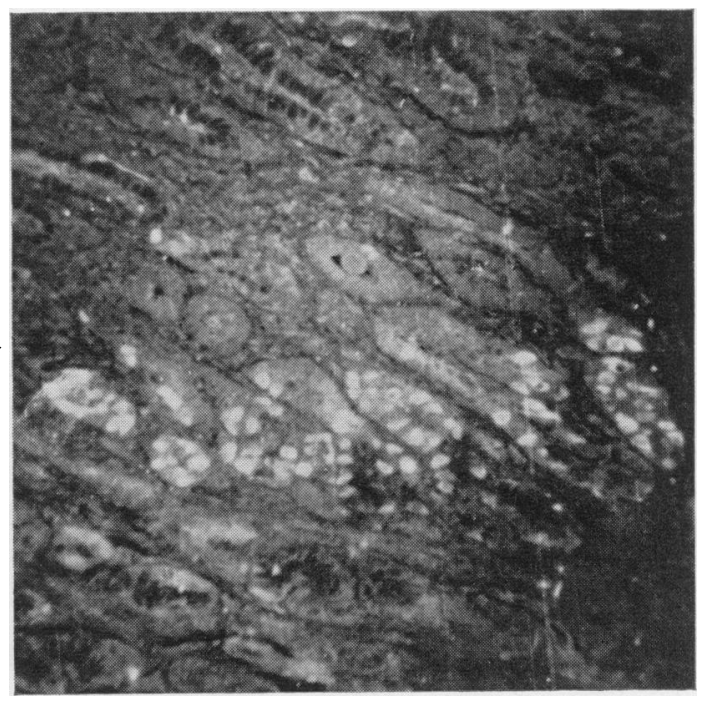

Fig. 2. Human stomach, pyloric region, from a case of acromegaly with hypersecretion (Kay test, 15 m-equiv/hour; post-histamine, 24 m-equiv/hour). The mid portions of the gastric glands show hyperplasia of the $G$ cells $(\times 87)$.

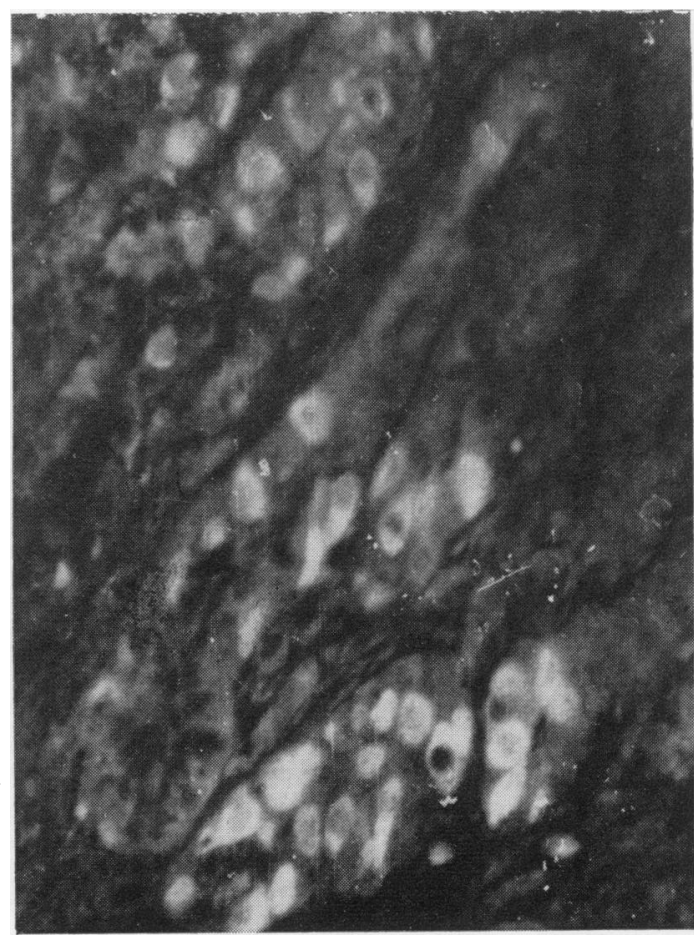

FIG. 4. Human pyloric antrum, as in Fig. 2 (hypersecretion). Very many more $G$ cells are present and the degree of fluorescence shown by the individual cells is raised by comparison with the control case shown in Fig. $3(\times 420)$. 
serum, gave uniformly negative results. In normal cases the number of fluorescing $G$ cells in the deep and middle portions of the gastric glands was variable. The average density of cells is illustrated in Fig. 1, and it can be observed that several glands contain few $\mathbf{G}$ cells or none at all. Samples of antra from cases with proven hypersecretion of acid also gave somewhat variable results, although in no case where the sampling was adequate were fewer fluorescing $G$ cells seen. The degree of hyperplasia of $G$ cells was in some cases very striking indeed. Figure 2 shows the pyloric glands from a case of hypersecretion in which almost the whole length of the glands is shown. There is a wide band of fluorescing $\mathbf{G}$ cells extending through the whole of the mid-zone portion (the region in which both we and McGuigan find the normal $\mathbf{G}$ cells to be preferentially located). Figures 3 and 4 show normal and hypersecreting pyloric glands at a higher magnification. While quantitation of fluorescence has not been attempted the degree of fluorescence does appear to be somewhat higher in the hypersecreting cases than in the controls.

\section{Discussion}

The state of the $\mathrm{G}$ cells in different physiological conditions has so far been inadequately investigated. Their identification as the source of gastrin has indeed been too recently achieved (McGuigan, 1968). Because the general morphology and cytochemistry of the cells has also been determined (Solcia et al, 1969) it is possible to derive some information from previous studies on the pyloric antrum, but no general correlation of $G$ cells and serum gastrin levels has yet been attempted. The levels of the latter are observed to rise with age, from the normal 100 units to about 400 . They are higher in cases of pernicious anaemia (up to 2,000) and highest in cases of Zollinger-Ellison syndrome (above 2,000). We should expect to find G-cell hyperplasia, on this basis, in old age and in pernicious anaemia. On the other hand, in cases with primary hypersecretion of acid we might expect to find some degree of acid inhibition with degranulation or even hypoplasia of the $G$ cells. The previous paper (Pearse, Coulling, Weavers, and Friesen, 1970) reports morphological observations on antral mucosa from nine cases of duodenal ulcer. Subject to individual variation the general findings were hyperplasia and degranulation of the $\Omega$

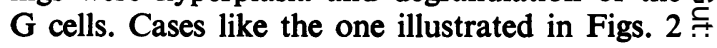
and 4 are to be regarded as hypersecretors $\vec{F}$ secondary to the stimulus of raised G-cell $\stackrel{0}{\rightarrow}$ activity and gastrin secretion.

The results presented here are essentially $\frac{\bar{\sigma}}{\overline{0}}$ preliminary. We have been unable to examine $\frac{\vec{\sigma}}{\vec{\alpha}}$ any case of pernicious anaemia but the results $\propto$ obtained by Rubin (1969) are probably significant. ळै He describes a striking hyperplasia of endocrine- $\overrightarrow{0}$ like cells (almost certainly $\mathbf{G}$ cells) in suction biopsies of atrophic gastric mucosa.

We conclude that immunofluorescence studies of gastrin levels in human gastric biopsies can

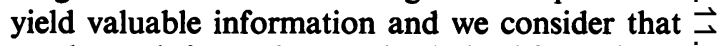
much new information can be derived from these, particularly if they are combined with studies using staining and other cytochemical techniques in addition to immunofluorescence.

\section{Addendum}

Five cases of pernicious anaemia have now been $\vec{\theta}$ examined by Polak, Coulling, and Pearse. Confirmation of G-cell hyperplasia has been obtained in the fundic mucosa. The majority of cells have a low granule content and low immunofluorescence.

\section{References}

Bussolati, G., and Pearse, A. G. E. (1970). Immunofluorescent localization of the gastrin-secreting $\mathbf{G}$ cell in the pyloric antrum of the pig. Histochemie, 21, 1-4

Graham, R. C., Jr., and Karnovsky, M. J. (1966). The early stage of absorption of injected horseradish peroxidase in the proximal tubules of mouse kidney: ultrastructural cytochemistry by a new technique. J. Histochem. Cytochem., 14, 291-302.

McGuigan, J. E. (1968). Gastric mucosal intracellular localization of gastrin by immunofluorescence. Gastroenterology, 55, 315-327.

Pearse, A. G. E., Coulling, I., Weavers, B., and Friesen, S. (1970). The endocrine polypeptide cells of the human stomach, duodenum and jejunum. Gut, 11, 649-658.

Rubin, W. (1969). Proliferation of endocrine-like (enterochromaffin) cells in atrophic gastric mucosa. Gastroenter- $N$ ology, 57, 641-648.

Solcia, E., Vassallo, G., and Capella, C. (1969). Studies on the N $\mathbf{G}$ cells of the pyloric mucosa, the probable site of gastrin secretion. Gut, 10, 379-388.

Wood, B. T., Thompson, S. H., and Goldstein, G. (1965). $\sigma$ Fluorescent antibody staining. III. Preparation of fluorescein isothiocyanate-labelled antibodies. J. Immunol., 95, $255-229$. 